\title{
Metodologias ativas no processo de ensino e aprendizagem de projeto arquitetônico
}

\author{
Active methodologies in the teaching and learning process of architectural design \\ Metodologías activas en el proceso de enseñanza y aprendizaje del diseño arquitectónico
}

Recebido: 01/05/2021 | Revisado: 09/05/2021 | Aceito: 11/05/2021 | Publicado: 25/05/2021

\author{
Jonathan Felipe da Silva \\ ORCID: https://orcid.org/0000-0003-2677-2984 \\ Instituto Federal de Educação, Ciência e Tecnologia do Ceará, Brasil \\ E-mail: jonathan.silva@ifce.edu.br \\ Sandro César Silveira Jucá \\ ORCID: https://orcid.org/0000-0002-8085-7543 \\ Instituto Federal de Educação, Ciência e Tecnologia do Ceará, Brasil \\ E-mail: sandrojuca@ifce.edu.br \\ Jefferson Queiroz Lima \\ ORCID: https://orcid.org/0000-0002-3250-1411 \\ Instituto Federal de Educação, Ciência e Tecnologia do Ceará, Brasil \\ E-mail: jeffersonlima@ifce.edu.br \\ Solonildo Almeida da Silva \\ ORCID: https://orcid.org/0000-0001-5932-1106 \\ Instituto Federal de Educação, Ciência e Tecnologia do Ceará, Brasil \\ E-mail: solonildo@ifce.edu.br
}

\begin{abstract}
Resumo
Este artigo tem como objetivo analisar a capacidade das metodologias ativas de potencializar o processo de ensino e aprendizagem de projeto arquitetônico no curso de graduação em Arquitetura e Urbanismo, ofertado pela Universidade Federal do Ceará. A metodologia presente na pesquisa está caracterizada como um estudo descritivo, de abordagem qualitativa, do tipo relato de experiência, onde são apresentadas propostas de ensino, em especial a utilização da realidade aumentada (RA), para os alunos presentes na disciplina de projeto arquitetônico e a aferição deste aprendizado em sala de aula. Os resultados obtidos expõem o êxito da utilização das metodologias ativas como ferramentas de aprendizagem, motivando o aluno a dedicar-se ainda mais à disciplina ao construir um conhecimento mais efetivo. A conclusão da pesquisa ratifica o potencial transformador destas metodologias dentro do processo de ensino e aprendizagem onde o docente tem a possibilidade de trabalhar, em sala de aula, diversas ferramentas que o auxiliam a abordar o conteúdo, e a trazer o aluno para o centro da discussão e reflexão. Devido às restrições causadas pela pandemia do Covid-19, como o desenvolvimento das aulas de forma virtual, estas ferramentas se aplicam de forma ainda mais necessária na esfera educacional.
\end{abstract}

Palavras-chave: Aprendizagem; Ensino; Metodologia ativa; Projeto arquitetônico; Realidade aumentada.

\begin{abstract}
This article aims to analyze the capacity of active methodologies to enhance the teaching and learning process of architectural design in the undergraduate course in Architecture and Urbanism, offered by the Federal University of Ceará. The methodology present in the research is characterized as a descriptive study, with a qualitative approach, of the experience report type, where teaching proposals are presented, especially the use of augmented reality (AR), for the students present in the discipline of architectural design and the measurement of this learning in the classroom. The results obtained show the successful use of active methodologies as learning tools, motivating the student to dedicate himself even more to the discipline when building more effective knowledge. The conclusion of the research confirms the transformative potential of these methodologies within the teaching and learning process where the teacher has the possibility to work, in the classroom, several tools that help him to approach the content, and to bring the student to the center of the discussion and reflection. Due to the restrictions caused by the Covid-19 pandemic, such as the development of classes in a virtual way, these tools are applied even more necessary in the educational sphere.
\end{abstract}

Keywords: Learning; Teaching; Active methodology; Architectural project; Augmented reality.

\section{Resumen}

Este artículo tiene como objetivo analizar la capacidad de las metodologías activas para potenciar el proceso de enseñanza y aprendizaje del diseño arquitectónico en la carrera de pregrado en Arquitectura y Urbanismo, impartida por la Universidad Federal de Ceará. La metodología presente en la investigación se caracteriza por ser un estudio descriptivo, con enfoque cualitativo, del tipo relato de experiencia, donde se presentan propuestas didácticas, especialmente el uso de la realidad aumentada (AR), para los estudiantes presentes en la disciplina de diseño 
arquitectónico. y la medición de este aprendizaje en el aula. Los resultados obtenidos muestran el uso exitoso de metodologías activas como herramientas de aprendizaje, motivando al alumno a dedicarse aún más a la disciplina a la hora de construir conocimientos más efectivos. La conclusión de la investigación confirma el potencial transformador de estas metodologías dentro del proceso de enseñanza y aprendizaje donde el docente tiene la posibilidad de trabajar, en el aula, varias herramientas que le ayudan a acercarse al contenido, y a llevar al alumno al centro de la enseñanza. la discusión y la reflexión. Debido a las restricciones provocadas por la pandemia Covid-19, como el desarrollo de clases de forma virtual, estas herramientas se aplican aún más necesarias en el ámbito educativo.

Palabras clave: Aprendizaje; Enseñando; Metodología activa; Proyecto arquitectónico; Realidad aumentada.

\section{Introdução}

O projeto arquitetônico é considerado um documento essencial para que seja efetivada uma construção de forma segura, econômica e eficaz. É uma concretização de ideias e anseios daqueles que demandam o projeto, vinculados ao conhecimento teórico e prático do projetista. Por ser considerado um documento base, é necessário para a execução dos projetos complementares, a exemplo do projeto estrutural, hidrossanitário, entre outros.

O profissional projetista, entre eles o arquiteto, precisa desenvolver a sua visão e abstração tridimensional de forma plena, para que seja construído um bom entendimento do projeto e, consequentemente, elaborar trabalhos mais sustentáveis e com maiores detalhamentos, reduzindo o custo final da obra e também o desperdício de materiais. Seguindo esta afirmação, Zevi (1984) analisa o desafio da discrepância entre o projeto no campo bidimensional e a sua respectiva abstração no âmbito tridimensional.

Assim, para mitigar esta dificuldade, é preciso reservar, no percurso das disciplinas de projeto arquitetônico, uma atenção especial aos exercícios de treinamento desta abstração espacial. O professor necessita buscar alternativas para desenvolver, no aluno, o interesse e a capacidade exigidas para a boa compreensão do projeto e de sua construção. A fim de que o ensino de projeto arquitetônico seja efetivado, é necessária, ainda, a apropriação pelo discente de diversas habilidades específicas, tais como o entendimento das normas relacionadas ao projeto, além do estudo sobre os aspectos históricos, geográficos, de conforto ambiental, ventilação, insolação, entre outros.

Assim, todos estes requisitos estão presentes na elaboração do projeto, e o professor em diversas vezes possui a dificuldade de trabalhar com os alunos utilizando apenas o quadro e computadores com softwares bidimensionais. Uma solução viável e indicada nesta pesquisa seria a utilização das metodologias ativas inseridas de forma eficaz na disciplina de projeto arquitetônico.

Estas metodologias, desenvolvidas de forma mais notável nas últimas décadas do século XX, são um conjunto de estratégias para trazer o aluno para o ponto central do processo de aprendizado (Novaes et al., 2021). Segundo Moreira, Kujawa \& Almeida (2018), representam uma forma de inovação no processo de ensino aprendizagem, onde o professor deixaria de apenas transmitir informações acumuladas e passaria a ser um facilitador para o desenvolvimento do aluno em suas competências.

De acordo com Prado (2015), não há incertezas sobre a urgência em modificar a forma como o conhecimento é desenvolvido em sala de aula, e este processo deve ser compreendido pelos estudantes. Esta reflexão traz consigo a necessidade de desenvolver aulas mais participativas e mais ativas, onde o professor mediaria o percurso pedagógico do aluno.

Tais metodologias, segundo Faraco et al. (2020), são aplicadas no processo educacional por distintas formas, entre elas encontram-se: Problem-Based Learnig (aprendizagem baseada na resolução de problemas - ABP), Project-Oriented Learnig (aprendizagem baseada em projetos - POL), Team-Based Learning (aprendizagem em equipe - TBL) e Peer Instruction (aprendizagem em pares - PI). Ainda segundo os autores, a escolha para utilização destas metodologias varia conforme o currículo de cada curso, aliada à capacidade dos professores em dominar as ferramentas necessárias. 
No presente artigo, foi desenvolvida a estratégia de ABP ou Problem-Based Learning (PBL), que foi observada de forma mais notável nas ações da Faculdade de Medicina da Universidade de McMaster, Canadá, no ano de 1969 (Filatro \& Cavalcanti, 2018). A ABP, conforme Prometilla (2017), é considerada por muitos especialistas da esfera educacional como uma forma de ensino superior às atividades clássicas e tradicionais.

Destaca-se, segundo Gonçalves, Gonçalves e Gonçalves (2020), as características principais encontradas no ensino tradicional, como a centralidade do processo na figura do professor, a exposição potencializada de aulas expositivas, o privilégio da reprodução do conhecimento, as avaliações periódicas, entre outras. A ABP se apresenta como um processo de melhoria da relação entre ensino e aprendizagem, uma vez que o currículo seria temático e interdisciplinar, o estímulo a trabalhos em grupos e um aprendizado mais independente seriam estratégias recomendadas para a superação da dificuldade de apreensão de conhecimento pelo aluno (Gonçalves, Gonçalves e Gonçalves, 2020).

Através da problematização, conforme abordado em Chaves et al. (2020), o aluno é incentivado a desenvolver uma postura cada vez mais autônoma e ativa diante das situações, sempre buscando uma solução real. Esta estratégia aproximaria o aluno das situações vivenciadas dentro do campo laboral, se desenvolvendo como um profissional ainda mais preparado para atuar na sua transformação (Diesel, Baldez \& Martins, 2017 e Morán, 2015).

Dessa forma, o objetivo da ABP seria uma proposta pedagógica voltada para a resolução de problemas, e não para a simples separação de disciplinas. Haveria um incentivo à interdisciplinaridade e a uma sincronia maior entre professor, aluno e conteúdo abordado.

Além disso, podem ser adicionados à reflexão os elementos conceituais relativos à Didática Profissional (DP) que, segundo Alves (2020), representa uma importante corrente francesa do final dos anos 90 e que reflete sobre a atividade do professor, em especial aqueles dedicados a lecionar disciplinas específicas e derivadas do trabalho. A DP busca compreender a formação do professor e suas concepções epistêmicas e pragmáticas. Assim, a utilização das metodologias ativas aliadas à DP traz uma compreensão da formação do professor e sua atuação em sala de aula, para que ocorra de forma acessível aos alunos para a construção de um conhecimento mais efetivo.

A tecnologia se apresenta como uma ferramenta essencial para o processo de ensino e aprendizagem. Segundo Cordeiro (2020), a evolução das tecnologias digitais de informação permitiu que os docentes encontrassem maior dinamicidade da informação e de recursos físicos em favor dos discentes. Apesar de ainda diversos educadores se encontrarem resistentes às inovações tecnológicas de ensino, é evidente a potencialidade que as tecnologias de informação e comunicação (TICs) na educação, sendo esta uma das mais favorecidas com os avanços obtidos.

A pandemia do covo coronavírus (COVID-19) trouxe à tona uma maior necessidade de se apropriar das tecnologias, para que as aulas remotas pudessem ocorrer. Ferramentas de gravação das aulas, de edição de vídeos, além de encontros virtuais realizados por diversos meios tiveram que ser apropriados pelo professor. $\mathrm{O}$ acesso à internet tornou-se fundamental para o desenvolvimento das estratégias pedagógicas, como a educação à distância, definida pelo Ministério da Educação do Brasil (MEC) como uma modalidade educacional na qual alunos e professores estão separados física ou temporalmente e por isso, sendo preciso o uso de meios e tecnologias de informação e comunicação (MEC, 2018).

Assim, a tecnologia tornou-se base para que o processo de ensino e aprendizagem seja efetivado, sendo ainda mais evidente nas condições de limitação impostas pela referida pandemia. A adoção de metodologias ativas é considerada ainda mais essencial para que o aluno seja motivado também durante as aulas remotas. O professor deve buscar meios para que o conteúdo seja compreendido e motivo de reflexão por todos os participantes envolvidos no processo.

$\mathrm{O}$ ensino da disciplina de projeto arquitetônico, que necessitaria de encontros presenciais para que o discente tenha contato com os projetos físicos, precisa reinventar-se e assumir este desafio de ser viável também durante as aulas à distância. É 
preciso que o professor responsável por este conteúdo esteja consciente da urgência em adaptar sua metodologia sem desviar-se dos objetivos definidos. O professor e o aluno, por meio das aulas remotas e através de exercícios, precisam dominar as ferramentas disponíveis para uma melhor compreensão e elaboração dos projetos arquitetônicos

Seguindo os conceitos definidos pela estratégia da ABP discutida anteriormente, foi considerada, neste artigo, a estratégia de uso da realidade aumentada (AR) ou augmented reality (RA) como uma alternativa viável para potencializar a aprendizagem nesta área específica de projeto arquitetônico. Por se fundar na ideia de resolução de desafios, a ABP traz consigo uma reflexão sobre o processo como um todo, além de incentivar a interdisciplinaridade, a inovação e a criatividade por parte do aluno. A utilização da tecnologia é bastante viável nesta metodologia, para que o educador tenha a possibilidade de estar mais próximo do educando e o desafiando a aumentar seu horizonte de conhecimentos.

Conforme Alves (2020), desde as primeiras civilizações, o ser humano buscou desenvolver representações da sua realidade por meio de pinturas, cinema, entre outros. Assim, com a possibilidade de utilização do computador, as formas de representação passaram a ocorrer através de vídeos, jogos ou demais alternativas virtuais. A RA foi desenvolvida com o objetivo de complementar o mundo real através de informações virtuais, sendo o espeço real a base de todo o processo Azuma (2001). Ainda segundo o autor, a distinção da RA para a realidade virtual (RV), consiste que esta última se apropria do mundo virtual como base para as informações, retirando o usuário de forma completa das percepções reais.

Para acessar os elementos de RA, é preciso um software específico, permitindo a câmera de um aparelho (celular ou tablet) realizar a leitura de um marcador (uma espécie de código padronizado - $Q R$ Code) e projetar, em seguida, as informações virtuais associadas aos elementos reais expostos pela própria câmera. A Figura 1 exemplifica a utilização desta tecnologia.

Figura 1: exemplo de utilização da RA no projeto arquitetônico

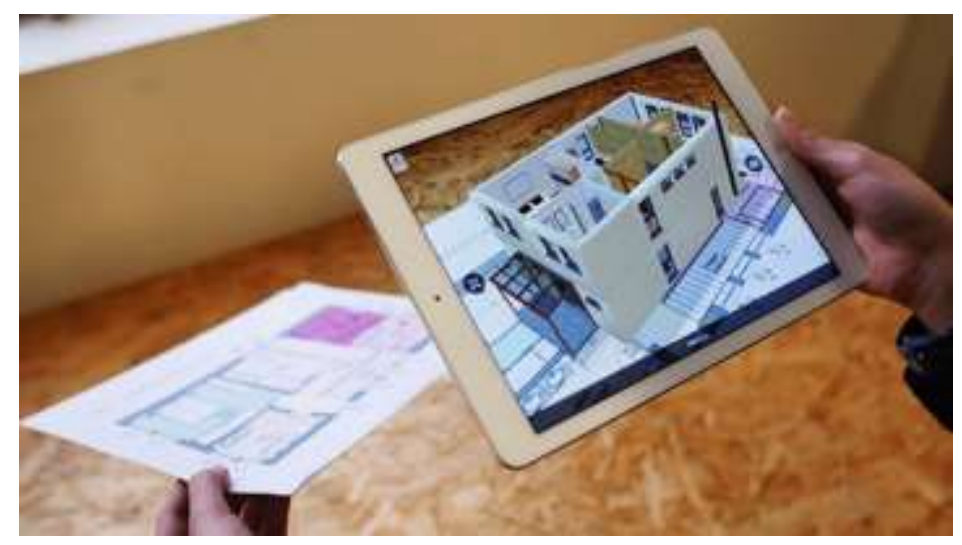

Fonte: Goingreen (2019).

A Figura 1 expõe um exemplo de utilização de RA dentro do processo de projeto arquitetônico, mostrando a facilidade de visualização e entendimento do projeto ao permitir uma interação maior com a proposta de edificação.

A RA assume um grande potencial, como metodologia ativa, de facilitar o ensino e o aprendizado não apenas de projeto arquitetônico, mas de várias disciplinas ofertadas. A RA é considerada uma ferramenta bastante utilizada no ambiente educacional, devido à sua capacidade de trazer contribuições para a percepção e para a motivação dos alunos em sala de aula (Manrique-Juan et al., 2017).

Assim, a problematização encontrada no entendimento e na concepção dos projetos arquitetônicos seria trabalhada por meio de recursos da RA. O aluno teria a oportunidade de compreender o projeto de forma integral e suas especificidades, ao visualizar a edificação de forma tridimensional. E o docente teria um notável benefício ao discutir o conteúdo tanto de forma 
presencial quanto remota, apenas com a utilização de poucos recursos tecnológicos. Um outro benefício seria considerar o celular do aluno como uma poderosa ferramenta pedagógica (Vieira et al., 2018).

Além da utilização como potencializador do processo de ensino e aprendizagem de projeto arquitetônico, a RA tem a capacidade de auxiliar nas diversas disciplinas, uma vez que torna acessível o contato com o conteúdo, realizado de forma interativa e em tempo real.

Portanto, o objetivo deste artigo é analisar os conceitos e possibilidades relacionadas às metodologias ativas e suas contribuições para o ensino e aprendizagem de projeto arquitetônico. Para mensurar esta contribuição, foi realizado um estudo com discentes do curso de nível superior de bacharelado em arquitetura e urbanismo, ofertado pela Universidade Federal do Ceará (UFC). O problema abordado seria esta dificuldade por parte do projetista em compreender o projeto de forma integral, devido à dificuldade na sua formação e limitações impostas dentro das disciplinas de projeto arquitetônico. As metodologias ativas seriam, assim, uma alternativa bastante prática e eficiente para auxiliar tanto professor quanto alunos neste percurso pedagógico. A metodologia da pesquisa será abordada na seção seguinte.

\section{Metodologia}

A pesquisa trata-se de um estudo de caráter descritivo, com abordagem qualitativa e do tipo relato de experiência (Pereira et al. 2018), possibilitando a resolução dos desafios no campo da prática (Cortes, Padoin \& Berbel, 2018).

A experiência foi relatada através de uma simulação com um total de 5 (cinco) alunos do curso de bacharelado em Arquitetura e Urbanismo, ofertado pela Universidade Federal do Ceará (UFC), durante o ano de 2021. Esta experimentação ocorreu por meio virtual, sendo a comunicação realizada por meio do sítio Google Meet $^{1}$, onde foi possível interagir com os discentes e desenvolver a etapa prática da pesquisa.

Foi desenvolvido com os alunos, inicialmente, um projeto de uma residência fictícia, de apenas 1 (um) pavimento, através do software Autocad ${ }^{\circledR}$ e de modo bidimensional. Neste projeto, foram contempladas as plantas do pavimento térreo, planta de cobertura, cortes e fachadas.

Desta forma, ao simular uma situação real de projeto, foram discutidos, durante o seu desenvolvimento, questões específicas, como dimensões mínimas, organização espacial, ventilação, insolação, conforto e acessibilidade. Foram abordadas, ainda, as normas relacionadas ao desenho técnico, para uma representação das simbologias arquitetônicas de forma correta.

Posteriormente, foi construído com os discentes o projeto tridimensional desta edificação, por meio do software SketchUp®, sendo possível o entendimento, além da utilização do próprio software, da forma e de elementos da edificação. Ao ser desenvolvido no plano tridimensional, os alunos ampliaram seu horizonte de compreensão do projeto antes representado apenas no campo bidimensional. Foi possível compreender, por exemplo, as escalas e dimensões de cada elemento interno e externo à edificação.

Ao concluir a etapa projetual, orientou-se aos alunos realizar uma exportação do projeto para o software de RA denominado Augin ${ }^{\circledR}$, gerando um marcador específico para o produto. Desta forma, foi possível compreender as possibilidades da RA para o entendimento da edificação como um todo, além da facilidade em transportar o projeto para expor a algum cliente ou em congressos e pesquisas, bastando apenas um smartphone ou tablet e a impressão de um marcador ou mesmo definindo uma superfície plana.

\footnotetext{
${ }^{1}$ https://meet.google.com/.
} 
Posteriormente, foi aplicado um questionário final com os participantes, para mensurar o nível de aprendizado de projeto arquitetônico, utilizando a RA como ferramenta. Com os resultados obtidos, notou-se que a dificuldade de visualização tridimensional dos alunos foi mitigada, comparando com alunos que não participaram da pesquisa.

Após ser apresentada a RA na forma prática, aplicada ao projeto da residência, houve uma discussão sobre as obras de alguns autores relevantes para o tema, tais como Araújo (2018), Moreira \& Ruschel (2015), Terra \& Augusto (2019) Lopes, Vidotto, Pozzebom \& Ferenhof (2019), Silva (2018) e Zorzal, Jorge \& Costa (2018), refletindo sobre a importância da RA na educação.

Desta forma, foi possível trabalhar os aspectos teóricos e práticos desta ferramenta, e os alunos puderam compreender a importância desta metodologia ativa para as suas formações como arquitetos mais preparados e seguros em sua profissão tanto para o mercado de trabalho quanto como futuros pesquisadores da área.

\section{Resultados e Discussão}

Partindo do conceito das metodologias ativas, em especial a ABP, foi possível contribuir para a mitigação de uma das maiores dificuldades apresentadas pelos alunos quando o assunto é projeto arquitetônico: a capacidade de abstrair de forma tridimensional e completa a edificação representada no projeto padrão, que se apresenta em forma bidimensional. Os 5 (cinco) alunos do curso de bacharelado em arquitetura e urbanismo da UFC selecionados para a pesquisa comprovaram que possuíam acesso à internet e que possuíam também um smartphone ou tablet, para o desenvolvimento da atividade.

Durante a primeira etapa de desenvolvimento do projeto arquitetônico de uma residência fictícia através do Autocad®, foram discutidas as normas vigentes aplicadas à atividade, tais como a Norma Brasileira (NBR) 9050/2015, que trata sobre conceitos de acessibilidade nas edificações; a NBR 15575/2013, que aborda sobre o desempenho em edificações habitacionais; além da NBR 13532/95, que discute sobre a elaboração de projetos arquitetônicos de edificações. Todas estas normas deram base à construção do projeto de forma segura. Assim, os alunos puderam apreender a legislação anteriormente à concepção projetual.

Seguindo com a interdisciplinaridade adotada, através da plataforma Google Meet, houve o início do desenvolvimento do projeto no software Autocad® de forma individual. Foi apresentado o programa de necessidades, que representa um documento que contém o conjunto das necessidades sociais e funcionais para um determinado espaço. Representa a base para o desenvolvimento de um projeto, onde estão presentes os ambientes e suas interrelações desejáveis.

A partir deste programa, iniciou-se a fase de desenvolvimento do projeto. Após uma discussão sobre a melhor organização dos espaços internos e materiais da edificação, foi apresentado o projeto final confeccionado de forma que todos os participantes da pesquisa dessem suas contribuições. As Figuras 2 e 3 ilustram o resultado do projeto da residência: 
Figura 2: Planta baixa desenvolvida através do Autocad®.

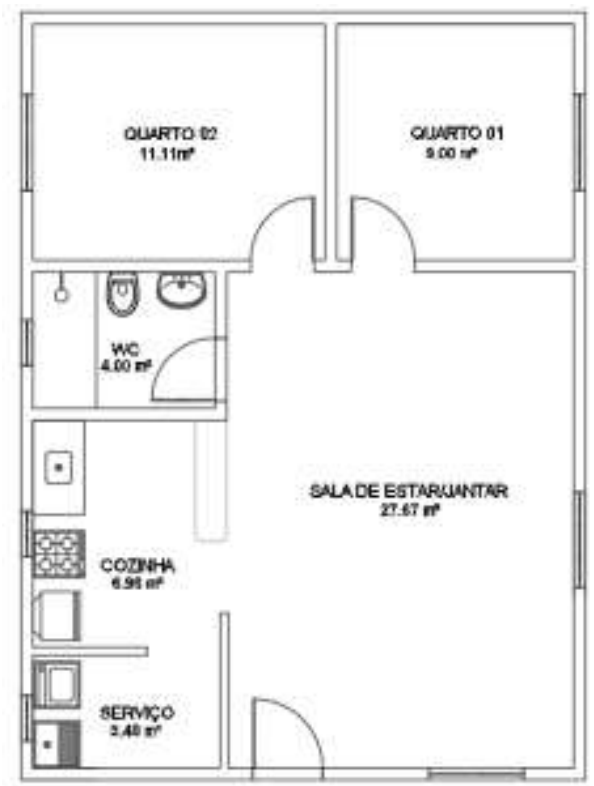

Fonte: Autores (2021).

Figura 3: Projetos da residência desenvolvidos através do Autocad®.

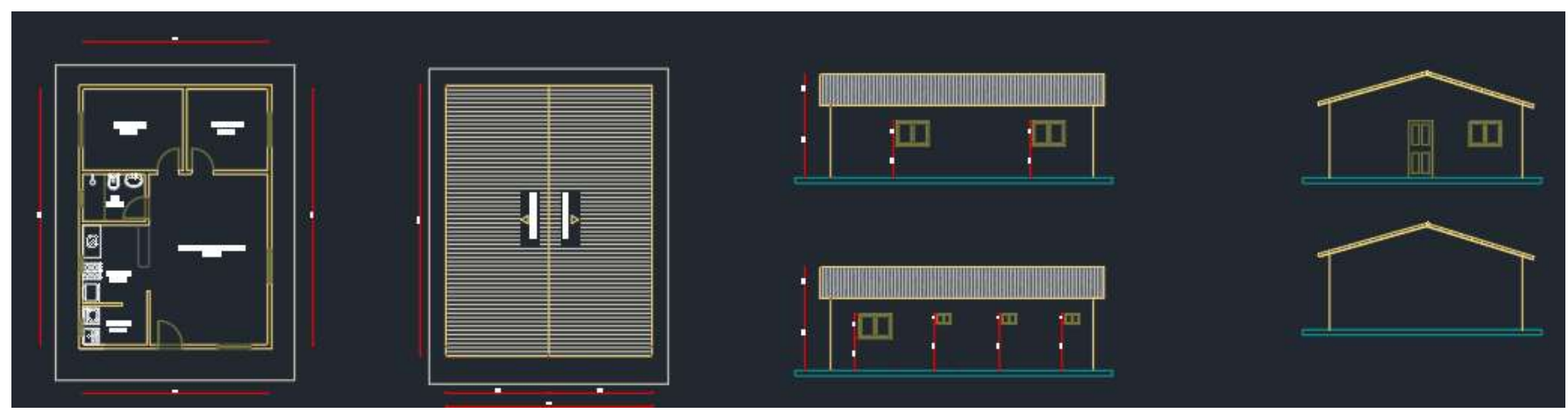

Fonte: Autores (2021).

Nas Figuras 2 e 3, é possível notar os detalhes do projeto solicitado aos participantes. O projeto consiste em uma residência simples, com apenas um pavimento e com um programa de necessidades enxuto.

A fase posterior ao desenvolvimento do projeto de forma bidimensional deu-se no software Sketchup®, onde foi possível trabalhar com os participantes os conceitos relativos à representação tridimensional, além de discutir sobre a escolha dos materiais de revestimento mais apropriados. Com isso, a equipe de participantes teve a oportunidade de refletir de forma integrada sobre as melhores alternativas projetuais.

A estratégia de utilização do tipo de metodologia ativa ABP revela a importância de se discutir com problemas reais, a fim de encontrar soluções viáveis e racionais para o projeto. Desta forma, os alunos, por meio do Sketchup®, puderam desenvolver suas habilidades de interpretação do projeto bidimensional, ao moldá-lo para uma apresentação tridimensional. A Figura 4 apresenta o resultado da modelagem por meio do referido software: 
Figura 4: modelo tridimensional desenvolvido pelos participantes através do Sketchup®.

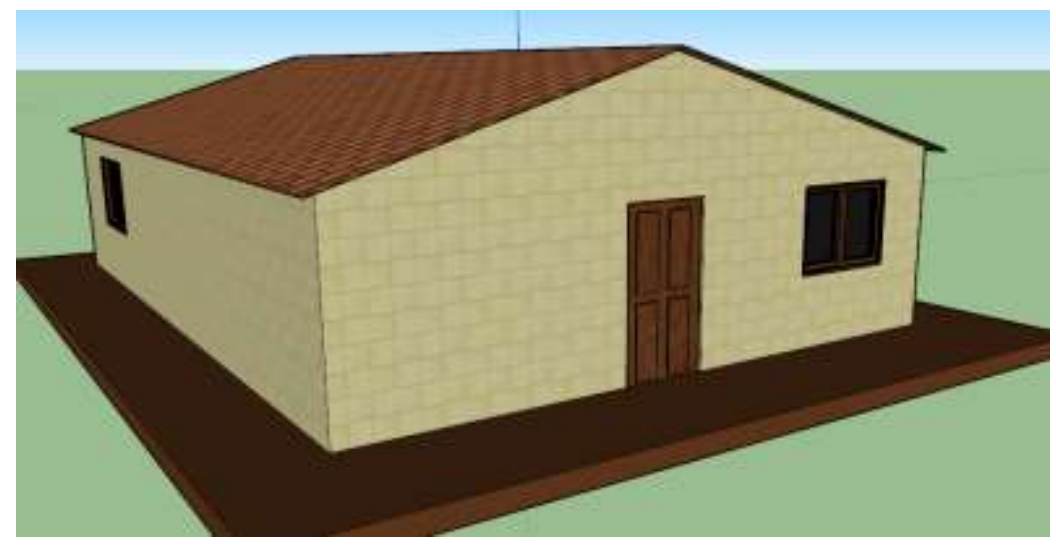

Fonte: Autores (2021).

A Figura 4 expõe os detalhes da modelagem tridimensional da residência. Foram utilizados materiais de revestimento como cerâmica, telhado colonial e esquadrias de madeira.

Após a conclusão do modelo tridimensional, os participantes relataram o ganho notável de conhecimento, uma vez que houve uma discussão para a construção deste modelo. Foi perceptível que a ABP esteve evidente em mais esta etapa, pois a troca de informações ao longo da confecção do projeto levou à resolução de diversos problemas que se encontravam para alcançar este objetivo em comum.

Com o término da modelagem tridimensional, os alunos foram orientados a utilizar o aplicativo de RA denominado Augin ${ }^{\circledR}$ para inserir a edificação e ter a possibilidade de visualizá-la de modo interativo e portátil. Para isso, o primeiro passo foi realizar a instalação do aplicativo, que é disponibilizado de forma gratuita, através das plataformas Google Play Store e Apple Store. Em seguida, eles inseriram o modelo em suas contas criadas no software, possibilitando a visualização em RA da residência, por meio de um marcador, em que o usuário apontaria a câmera do seu dispositivo, gerando a projeção. A Figura 5 indica a forma apresentada pelo marcador padronizado.

Figura 5: Exemplo de marcador padronizado Augin ${ }^{\circledR}$.

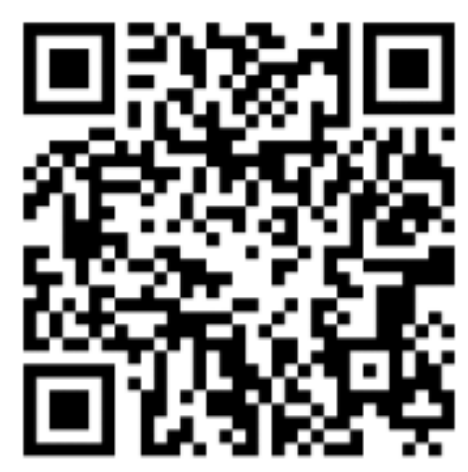

Fonte: Augin (2021).

Ao apontar a câmera do dispositivo para o marcador, foi possível gerar a edificação de forma tridimensional. Através do aplicativo Augin ${ }^{\circledR}$, os participantes tiveram a oportunidade de visualizar todos os elementos apresentados, sendo possível, ainda, a rotação do projeto, à medida em que era manuseado o marcador. Como o dispositivo móvel possuía, em sua 
configuração, o giroscópio ${ }^{2}$, tornou possível a projeção do modelo apenas definindo uma superfície plana, sem a obrigatoriedade da utilização do marcador. A Figura 6 a seguir ilustra como a edificação foi gerada pelo aplicativo, e projetada na tela do dispositivo utilizado:

Figura 6: Imagem apresentada pelo dispositivo, por meio do apontamento da câmera para o marcador de RA.

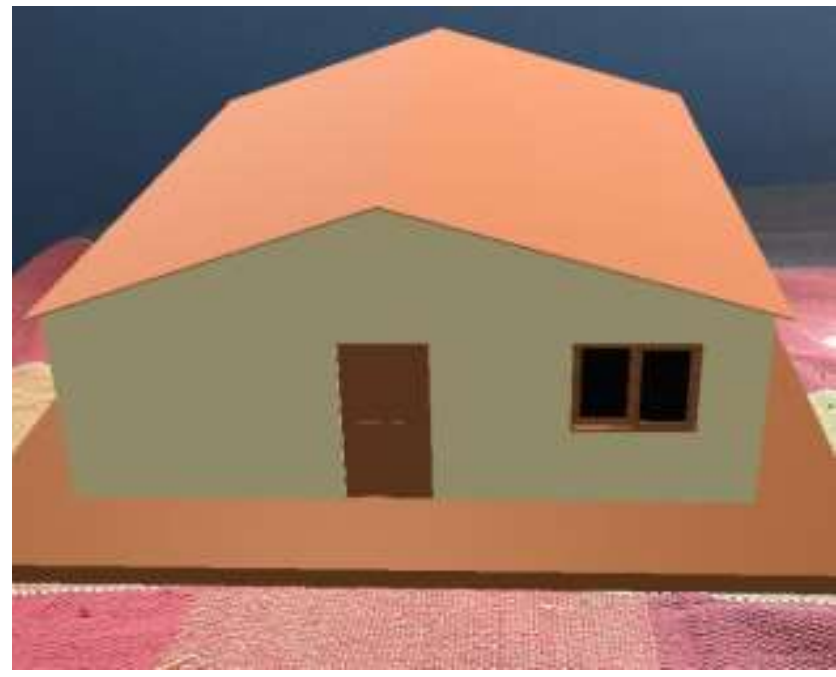

Fonte: Autores (2021).

A Figura 6 indica o resultado da visualização da edificação através da RA, sendo possível uma total interação com o modelo. Após a projeção da residência no software, os participantes interagiram com o modelo, revelando uma maior apreensão de entendimento do conjunto projetual. Foi possível, de forma integral, visualizar elementos internos e externos do objeto, rotacionar e alterar a escala a desejo do usuário.

Em seguida, foram discutidas algumas obras de autores relevantes para a temática da RA na educação, fazendo com que os participantes pudessem refletir também sobre os conceitos relacionados à atividade proposta. Na obra de Araújo (2018), são encontradas diversas possibilidades de aplicação da RA, como a exemplo da construção civil. Moreira \& Ruschel (2015) abordam sobre a relevância desta tecnologia para o projeto final. Já Terra \& Augusto (2019), indicam o crescimento do mercado onde o profissional qualificado e formado com o auxílio da RA atua) Lopes, Vidotto, Pozzebom \& Ferenhof (2019) expõem as outras aplicações desta ferramenta em jogos, com o objetivo de representar um importante instrumento de aprendizagem. Silva (2018) sugere o laboratório de informática como espaço ideal para o desenvolvimento destas atividades tecnológicas na escola. E Zorzal, Jorge \& Costa (2018) mostram como a RA pode ser utilizada em outras disciplinas, tais como história e biologia.

Assim, esta estratégia permitiu compreender o projeto arquitetônico como um todo, desde a sua concepção até o resultado final, em sua modelagem tridimensional, abrangendo desde os conceitos teóricos, normas e recomendações até a escolha do melhor material e organização espacial.

\section{Considerações Finais}

Este relato de experiência ressaltou o papel importante das metodologias ativas no processo de ensino e aprendizagem, principalmente no campo do projeto arquitetônico. A utilização da metodologia ativa de aprendizagem baseada em problemas

\footnotetext{
${ }^{2}$ Um tipo de sensor encontrado nos dispositivos, possibilitando a definição do objeto em um espaço previamente definido. Após esta indicação, é permitido rotacionar a câmera, revelando as outras faces deste objeto.
} 
(ABP) revela-se como uma alternativa bastante eficaz para que o aluno compreenda de forma mais intensa os conceitos e especificações apresentadas pelos projetos. O desafio dos professores responsáveis por estas disciplinas seria apropriar-se das estratégias pedagógicas e também dos recursos tecnológicos disponíveis em favor do ensino.

As metodologias ativas se apresentam, desta forma, como uma potencialização do processo de ensino, uma vez que o aluno, ao ser o centro do processo, passa a assumir uma maior autonomia para construir o seu próprio conhecimento. O professor assumiria, desta forma, a função de orientar o percurso pedagógico do aluno, e trazer para sala de aula discussões com problemas reais para, em comum, chegar a uma solução viável.

A utilização da RA no processo educacional permite a abertura de horizontes de conhecimento, para que o docente defina novas estratégias, gerando motivação à turma. $\mathrm{O}$ ensino de projeto arquitetônico, que passa muitas vezes por dificuldades de apreensão dos objetivos pedagógicos, receberia uma outra forma de didática. O docente, antes limitado à lousa, se permite explorar novos caminhos e apresentá-los aos discentes, de forma que seja construído um interesse em comum pela disciplina em questão.

O experimento apresentado por esta pesquisa mostrou-se positivo para o aprendizado de projeto arquitetônico. Os participantes tiveram a oportunidade de compreender o processo como um todo, discutir as melhores soluções e apresentá-las como forma de um modelo tridimensional, onde foi possível transportar para outros locais, não limitando-se ao uso apenas do computador. Esta ferramenta também seria útil para os problemas profissionais reais que estes alunos enfrentarão, pois será permitido apresentar os projetos das edificações para a equipe de projetistas, além dos futuros clientes.

Portanto, conclui-se que a RA, apesar de não representar uma tecnologia nova, possui um grande potencial como ferramenta de ensino e aprendizagem de projeto arquitetônico. O professor, apropriando-se dos objetivos das metodologias ativas e das ferramentas tecnológicas, abre uma oportunidade para os alunos assumirem seu papel ativo na construção do conhecimento, fazendo com que superem os desafios encontrados durante o desenvolvimento do projeto. E mesmo durante as aulas remotas, resultado da estratégia de isolamento social gerado pela pandemia de Covid-19 no mundo, esta estratégia pedagógica seria de possível aplicação, uma vez que o aluno, na sua residência e com acesso à internet, seria capaz de acessar os recursos da RA e desenvolver os projetos solicitados pelo professor.

Para pesquisas futuras, uma sugestão seria a investigação sobre RA por meio de livros didáticos em versão digital, facilitando a forma de divulgação e, ao mesmo tempo, adotando os conceitos de sustentabilidade, pois não seria necessário a utilização de impressão física.

\section{Referências}

Alves, D.C. (2020). Conteúdo de marca e realidade virtual: experiências imersivas e envolvimento corporal do consumidor com o conteúdo. $43^{\circ}$ Congresso Brasileiro de Ciências da Comunicação. - Sociedade Brasileira de Estudos Interdisciplinares da Comunicação. 1-14.

Alves, F. R. V. (2020). Didática Profissional (DP): implicações para a formação de professores e o ensino de disciplinas específicas no Brasil. Revista Iberoamericana de Estudos em Educação. Araraquara. V.15, n.4. 1903-1918.

Araújo, A. N. D. (2018). Uso de realidade aumentada como auxílio para concepção de projetos arquitetônicos em BIM: experimentos de pesquisa aplicada desenvolvida em disciplinas de modelagem e BIM no curso de Arquitetura e Urbanismo da UFPB entre 2015 e 2017. Universidade Federal da Paraíba. Programa de Pós-Graduação em Arquitetura e Urbanismo. 1-138.

Ayer, S. K., Messner, J. I. \& Anumba, C.J. (2016). Augmented Reality Gaming in Sustainable Design Education. Journal of Architectural Engineering, v. 22, n. 1, p. 1-9.

Azuma, R. (2001). Recent advances in augmented reality. IEEE computer graphics and applications, v. 21, n. 6, p. 34-47.

Chaves, U. S. B, Martins, A. S., Costa, C. C. P., Bisagni, C., Vieira, M. L. C., Jesus, P.B. R. (2020). Relato de experiência da utilização de metodologias ativas na prática da monitoria de um curso de Enfermagem. Research, Society and Development. V. 9, n. 9. 1-15.

Cordeiro, K. M. A. (2020). O impacto da pandemia na educação: a utilização da tecnologia como ferramenta de ensino. IDAAM. 1-15. 
Cortes, L. F., Padoin, S. M. M., \& Berbel, N. A. N. (2018). Problematization Methodology and Convergent Healthcare Research: praxis proposal in research. Revista Brasileira de Enfermagem, 71(2), 440-445.

Diesel, A., Santos Baldez, A., \& Neumann Martins, S. (2017). Os princípios das metodologias ativas de ensino: uma abordagem teórica. Revista Thema, 14(1), 268-288.

Faraco, R. L. P. S., Almeida, A. C. V., Mourão, L. C., Leite, I. C. M., Amorim, S. M. \& Oliveira, M. A. (2020). Metodologias ativas no mestrado profissional em ensino na saúde: ampliando os espaços de construção do conhecimento. Research, Society and Development, v. 9, n. 6. 1-20.

Filatro, A. \& Cavalcanti, C. C. (2018) Metodologias Inovativas na educação presencial, a distância e corporativa. São Paulo: Saraiva Educação. 1 ed. 1-272.

Gonçalves, M. F., Gonçalves, A. M. \& Gonçalves, I. M. F. (2020). Aprendizagem baseada em problemas: uma abordagem no ensino superior na área da saúde. Revista Pemo. Universidade Estadual do Ceará. 1-12.

Lopes, L.M.D., Vidotto, K.N.S., Pozzebon, E. \& Ferenhof, H.A. (2019). Inovações Educacionais com o uso da Realidade Aumentada: uma revisão sistemática. EDUR - Educação em revista. Belo Horizonte. 1-33.

Manrique-Juan, C., Grostieta-Dominguez, Z. V. E., Rojas-Ruiz, R., Alencastre-Miranda, M., Muñoz-Gómez, L. \& Silva-Munõz, C. (2017). A Portable Augmented-Reality Anatomy Learning System Using a Depth Camera in Real Time. BioOne, v.79, n. 3, p. 176-183.

Ministério da Educação do Brasil. (2021). Educação à Distância. http://portal.mec.gov.br/instituicoes-credenciadas/educacao-superior-a-distancia.

Morán, J. (2015). Mudando a educação com metodologias ativas. In de Souza, C. A. \& Morales, O. E. T. (orgs.). Coleção Mídias Contemporâneas. Convergências Midiáticas, Educação e Cidadania: aproximações jovens. Vol. II. 15-33.

Moreira, D. A., Kujawa, H. \& Almeida, C. C. O. (2018). Aplicação de metodologias ativas dinamizam o ensino superior: um relato de caso no curso de arquitetura e urbanismo. IMED. 1-13.

Moreira, L. \& Ruschel, R. (2015). Realidade aumentada na visualização de soluções do projeto de arquitetura. XIX Congresso da Sociedade Ibero-americana de Gráfica Digital. Florianópolis. Vol. 2. 191-196

Novaes, M. A. B., Silva, E. S., Costa, M. K. R., Amorim, P. A., Machado, F. L. M., Machado, A. M. M. R., Moura, J. S., Paiva, C. R. B., Martins, I. S., Paulino, F. G. O., Araújo, M. N., Medeiros, J. L. \& André, A. S. (2021). Metodologias ativas no processo de ensino e de aprendizagem: alternativas didáticas emergentes. Research, Society and Development, v. 10, n. 4. 1-10.

Prado, A. (2015). Entendendo o aluno do século 21. Revista Educação e Evolução. 3-17.

Prometilla, M. A. B. (2017). Problem-based learning of process systems engineering and process integration concepts with metacognitive strategies: The case of Pgraphs for polygeneration systems. Applied Thermal Engineering, v. 127, 1317-1325.

Silva, I. A. (2018). O potencial da realidade aumentada na educação. Congresso Internacional de Educação e Tecnologias - Universidade Federal da Paraíba. São Carlos. 1-14

Tagliari, A. (2018). Modelos conceituais de trajetória e circulação no projeto arquitetônico. 5\% Arquitetura + Revista de Arte. Unicamp. 1-20.

Terra, F.B. \& Augusto, W.F.C. (2019). A utilização da realidade virtual e realidade aumentada na representação de projetos arquitetônicos. $19^{\circ}$ Congresso Nacional de Iniciação Científica. 10p. São Paulo. 1-10.

Vieira, H. V. P., Martinhon, P. T., Simões, A. L., Rocha, A. S. \& Sousa, C. (2018). Perspectivas do uso de aplicativos de celular como ferramenta pedagógica para o ensino de química. Revista Debates em Ensino de Química. 125-138.

Zevi, B. (1984) A linguagem Moderna da Arquitetura. Lisboa: Publicações Dom Quixote. 176p.

Zorzal, E. R., Jorge, J.A.P. \& Costa, G.G. (2018). Desafios e aplicações da realidade aumentada móvel na Educação. Revista Renote. UFRGS. V16. 10p. Porto Alegre. 1-10. 